\title{
Analysis of Long-term Care Insurance Demand of Megalopolis in China under the Background of Aging of Population-Take Shanghai as an Example ${ }^{\dagger}$
}

\author{
Guo Jing ${ }^{1}$, Xiaojun $\mathrm{Pan}^{2}$, Chengyi $\mathrm{Pu}^{1, *}$ \\ ${ }^{1}$ School of Insurance, Central University of Finance and Economics, Beijing 100081, China \\ ${ }^{2}$ Institute of Disaster Prevention and Mitigation, Beijing Normal University, Beijing 100028, China
}

\section{ARTICLE INFO}

Article History

Received 12 October 2020

Accepted 10 March 2021

Keywords

The demand for long-term care insurance

rapid aging of the population megacity

Megalopolis

Shanghai

\begin{abstract}
The development of Long-term Care Insurance (LTCI), which matches that people get old before becoming rich lag behind. The mega-urban agglomeration formed in the metropolitan area under the process of urbanization intensifies the demand for insurance driven by long-term care needs. This paper constructs a theoretical model to sort out the micro-action mechanism of LTCI products entering the production field through the consumption of corporate security services, and at the same time entering the consumption field in the form of security services demand from families, individuals and government agencies, it reveals that the differences in the micro-paths of LTCI products entering the enterprise production field and the household consumption field under different regional economic and social conditions. Then, using the GM $(1,1)$ model to analyze the demand for LTCI under the aging population trend of Shanghai, a super large city in China, we found that the situation and characteristics of Shanghai and Japan are similar, and the number of people who need care under the distribution of the elderly population in Shanghai from 2017 to 2027 is much lower than the number of people who need LTCI. Meanwhile, the current long-term nursing service has a large labor gap and high professional skills requirements, but the current salary is low. Besides, the share of elderly care institutions is small, which is not enough to support the current occupancy needs of severely disabled people. The actual development has a greater potential impact on public health expenditures, especially the increase in public health expenditures after the outbreak of the COVID-19 has brought uncertainty. Based on the above findings, we propose to introduce the successful mode of American political and commercial cooperation and the Japanese social security model to alleviate the rapid growth in the demand for LTCI accompanied by the aging trend in the mega-urban clusters formed in the urbanization process.
\end{abstract}

(C) 2021 The Authors. Published by Atlantis Press B.V.

This is an open access article distributed under the CC BY-NC 4.0 license (http://creativecommons.org/licenses/by-nc/4.0/).

\section{INTRODUCTION}

China's aging has the characteristics of getting older before getting rich, growing rapidly, and having a large population base. As of the end of 2018, according to the data of the National Bureau of Statistics, the number of people above 65 in China is 165.65 million, accounting for $11.94 \%$ of the total population. Among them, the old-age dependency ratio is $16.8 \%$, which means that every 100 working population in China needs to support 16.8 old people. The aging disability phenomenon in China's mega-cities represented by

“Corresponding author. Email: pucy@cufe.edu.cn

This article is supported by:

${ }^{1}$ The "Strategic Economy and Military-civilian Integration" Interdisciplinary Discipline (GJJ2019163) of Beijing Universities' high-precision disciplines, the "First-class

Discipline" construction project of the Central University of Finance and Economics,

"Research on Modernization of Catastrophe Risk Management and Natural Disaster

Governance”.

${ }^{2}$ The National Ethnic Affairs Commission in 2020 Supported by the project "Research on Rural Revitalization and Built-in Financial Innovation in Western Tibetan Areas in the Post-Poverty Era" (2020-GMB-030).

${ }^{3}$ National Natural Science Foundation of China, general project, project name: research on the mechanism and early warning mechanism of nursing risk in elderly care institutions; project batch number: 71871147 .
Shanghai is particularly serious. According to the data compiled from the Shanghai Sixth Census Bulletin, the disability rates of the $60-80$-year-olds in Shanghai are $5.0275 \%, 14.8139 \%$, and $32.7914 \%$, the severe aging trend has promoted the demand for elderly care.

Judging from the current development of the pension system in China, although the elderly, the disabled, and the need for care for diseases are extremely high, there is no directly compatible policy system and corresponding insurance products, the supporting facilities for elderly care need to be resolved urgently. Firstly, China's social security system is not perfect. Although the medical insurance of the five social insurances can solve the reimbursement of patients' medical expenses, most of the conditions that are not reimbursable are the exclusion of nursing and rehabilitation treatment expenses, that is, the expenses of nursing after the patient is discharged are not involved. Secondly, the supply of commercial nursing insurance products in China is in short supply. The major illness insurance in the current commercial insurance, its claims are mainly illness treatment and loss of income, etc., as a supplement to current social insurance, it also has limitations. On the one hand, there is a threshold for the payment of critical illness insurance. If the insured does not meet the payment conditions, commercial insurance companies 
will not pay. On the other hand, even if the payment conditions are met, the insured amount of the major illness insurance is a one-time payment, which does not apply to people who need long-term care. Therefore, to respond to the increasing demand for care under the background of China's aging, and to realize the social vision of "the elderly are dependent", China is currently conducting a pilot program of Long-term Care Insurance (LTCI).

Shanghai is China's super first-tier city, and its economic development is at the forefront of my country. The implementation of the system has exemplary significance for the country. Therefore, based on the goal of establishing a LTCI system for elderly care, it is necessary to start with the pre-judgment of the elderly disabled population to further clarify the care needs, to establish a scientific and reasonable LTCI system. This article chooses Shanghai as the research object, and mainly discusses and forecasts population as the introduction point.

\section{LITERATURE REVIEW}

\subsection{Summary of the Evolution of the Long-term Care Insurance System}

The original LTCI model originated in the United States in the 1970s. With the deepening of domestic aging in the United States, the care needs of the elderly are increasing year-by-year. In 1996, the Health Insurance Portability and Accountability Act came out and made a far-reaching reference to long-term insurance costs. Subsequently, many countries in Europe and Asia also have different forms of LTCI [1-4]. For example, in the dual mechanisms represented by France, although critical illness insurance covers most of the hospital's health expenditures in its medical system, the direct funding of family assistance only accounts for $9 \%$, requiring the introduction of compulsory care insurance. Commercial nursing insurance was introduced as a supplementary mechanism in subsequent years [5]. In the universal social security system represented by Japan, the form of payment is to provide benefits regardless of income or family status [6]. Generally speaking, the European region is mainly represented by the compulsory insurance of Germany and France, while the more developed countries in Asia are mainly Japan. The overall trend of global LTCI development is to change from the early government-sponsored model to a government-led corporate business model and then to a marketled corporate business model.

There is no mandatory LTCI system in the United States. The market-oriented model represented by the United States is essentially a joint guarantee of social insurance and commercial insurance, it is mainly operated by commercial insurance companies in the insurance market, with government intervention and subsidies. There are three main categories in social and commercial insurance [7]. The government mainly provides limited care protection to certain groups of people through Medicare and Medicaid, while the rest of the population is covered by commercial LTCI:

(1) Medical care (Medicare), which mainly covers the elderly above 65 years old, providing nursing care for the elderly for daily medical treatment, medication, and hospitalization within a certain number of days, individuals do not need to bear the cost.
(2) Medical assistance (Medicaid) is mainly operated by institutions, and the implementation subject is still the government. The subsidy fee is mainly for the operator of the institution since its original intention is to medical help, participants do not need to make personal payments.

(3) Long-term care cooperative plan is a form of cooperation between the government and the enterprise: The government takes care of the bottom line, the company conducts private operations, and the insured voluntarily insure, and the cost of insurance is higher than the previous two forms. The form of commercial insurance is mainly operated by commercial insurance companies, it is aimed at middle- and high-income groups and it is also a supplement to social insurance and aims to meet the willingness of higher-demand groups to purchase insurance.

Next is the universal social insurance model represented by Japan. The Japanese government introduced the "Long-term Care Preventive Measures" in 2006. In the past 10 years of development, several bills have been introduced [8]. Among them, the "Longterm Care Insurance Law" was reformed in 2015, covering all people above 40 years of age. There are two types of insurance subjects, divided by age: nationals between 40 and 65 years old are called No. 2 insurers, and nationals 65 and above are called No. 1 insurers; among them, according to the family and income, it is divided into five levels, as shown in Table 1. While providing long-term care protection, this measure is organizing community salons for the elderly above 65 years old. The cost of participation is relatively low, which can effectively screen them regularly to identify high-risk groups and promote social activities for the elderly.

\subsection{Research Progress of Long-term Care Insurance Demand Theory}

In the early discussion of LTCI theory by foreign scholars, it was mainly based on the assumption of rational people $[9,10]$. Most of them are thinking about the family's intergenerational relationship. It is found that the consumption of LTCI is affected by the income level of the children. Low-income children are more inclined to

Table 1 Overview of the implementation of long-term care insurance in Japan

\begin{tabular}{|c|c|c|}
\hline $\begin{array}{l}\text { Coverage } \\
\text { objects }\end{array}$ & Grades & Main component \\
\hline $\begin{array}{l}\text { No. } 1 \text { insurers } \\
\text { (People aged } \\
\text { above 65) }\end{array}$ & $\begin{array}{l}\text { Level 1: Recipients of social } \\
\text { assistance } \\
\text { Level 2: Municipalities tax- } \\
\text { exempt households, etc. } \\
\text { Level 3: Municipalities tax- } \\
\text { exempt individuals, etc. } \\
\text { Level 4: A taxon insured } \\
\text { income of fewer than } \\
2.5 \text { million yen } \\
\text { Level 5: A taxon insured } \\
\text { income of more than } \\
2.5 \text { million yen }\end{array}$ & $\begin{array}{l}\text { Home services: such as } \\
\text { home care, daycare, etc.; } \\
\text { community services: } \\
\text { daily life care, etc.; } \\
\text { institutional services: } \\
\text { nursing homes, health, } \\
\text { and medical institutions, } \\
\text { etc. Among them, the } \\
\text { No. } 2 \text { insurers are paid } \\
\text { for specific } 16 \text { diseases } \\
\text { (such as advanced cancer, } \\
\text { early-stage Alzheimer's }\end{array}$ \\
\hline $\begin{array}{l}\text { No. } 2 \text { insurers } \\
\text { (People aged } \\
\text { 40-65) }\end{array}$ & Other categories & $\begin{array}{l}\text { disease, cerebrovascular } \\
\text { disease, etc.). }\end{array}$ \\
\hline
\end{tabular}


take care of their parents in person [11-14] using HRS data analysis found that children's care for their parents will be replaced with income. Some scholars, based on the sociology of population, found that individuals with higher incomes and married people have more urgent needs for LTCI $[15,16]$. Although China's LTCI theory research started late, the results of research on aging are relatively rich, and it is generally believed that my country's aging has three major characteristics [17]. Firstly, is get old before getting rich. Our country has entered an aging society when the overall national strength is not high. Secondly, is unprepared to get old. China's pension system will face the strong impact of aging when it is not perfect. Thirdly is loneliness. Due to the widespread phenomenon of "fewer births" today, the elderly are prone to getting old and difficult to support due to various reasons such as disease and loneliness. In the government's response strategy, in the face of a major change in the demographic structure, the government needs to build strong public service measures for elderly care, centering on the actual needs of the elderly to ensure the quality of elderly care. Furthermore, with the acceleration of aging in China, the concept of "long-term care" has begun to be studied in depth. Many scholars have compared the experience of foreign LTCI implementation and believe that China should establish a LTCI mechanism with Chinese characteristics [18-21]. In recent years, the content of the current development model across the country is quite different, the development of LTCI can be carried out by providing customers with protection and avoiding moral hazard [22].

Furthermore, in the research methods of LTCI, the existing literature generally focuses on the demand factors of LTCI [23-25]. For example, cross-sectional data from the SHARE database (European Survey of Health, Aging and Retirement) to estimate the determinants of physical health for purchasing LTCI in France, the sample variables include BMI index and disease status, risky behavior and disability experience explain the characteristics of French LTCI demand [25], however, the mechanism design of how to design public policies to encourage the growth of long-term insurance is very lacking [26].

Domestic research is still in a situation of following foreign countries, for example, panel data analysis of the linear relationship between independent variables such as household savings, oldage dependency ratio, and the dependent variable LTCI premium income suggests the trend of the macro demand characteristics of LTCI [27]. Economic factors and education status substitute microscopic investigation Logistics probability model analysis to insure LTCI change factors and whether respondents prefer [28,29]. However, due to the short period of domestic pilot projects and the lack of data compared with foreign countries, domestic scholars mainly use questionnaire surveys to obtain data, and most often use the Logistics model for analysis.

In summary, regardless of the evolution of the LTCI system model or the development of LTCI theory, China lags behind foreign countries. However, domestic urbanization and aging have completed the rapid transformation of more than 300 years abroad in just above 30 years. In particular, the rate of aging is faster than abroad, and the rate of an ultra-high aging population is higher. The mega-urban agglomeration formed in the metropolitan area under the process of urbanization has intensified the demand for insurance driven by the demand for long-term care. In reality, there is an urgent need for LTCI system model reform and LTCI theoretical research to keep up with the needs of actual development, and build a true and worry-free life for the people. Because the LTCI has not been implemented for a long time, the relevant data is still blank, and the relevant empirical analysis is all based on questionnaire surveys, and there are few predictive analyses on the population. This article starts with the aging trend and the nursing needs of the elderly disabled population and uses the GM $(1,1)$ model to predict the population simulation to explore the insurance demand potential driven by the long-term care demand in the process of urbanization.

\section{ANALYSIS OF THE POTENTIAL MECHANISM OF LONG-TERM CARE INSURANCE}

\subsection{A Theoretical Model of Consumer Economic Activity in Demand for Long-term Care Insurance}

From the perspective of insurance demand acting on insurance consumption, as the current pilot LTCI in China is mainly social security mode, insurance consumption and welfare payment lag behind. Therefore, this paper puts insurance as a safety service of production and people's life into the general consumption category, and the demand for LTCI is measured by consumption function.

(1) The insured behavior is expressed by the production function as the input in the young age [30].

(2) The payment in the old age is measured by the utility function.

(3) Assuming that the production factor is a necessary condition of the production function, physical capital can be used as a risk backup when it is not insured, and insurance backup does not require excessive material backup, the insurance compensation (contingent claim) is a kind of market-oriented pre-preparation in advance. Therefore, physical capital and insurance consumption are replaceable. Based on the academic works of related scholars [31,32] this article improves the Cobb-Douglas production function: $Q=A L^{\alpha} K^{\beta}$. Let $K(t)$ be the capital stock, $C(t)$ be the consumption of general commodities, and $E(t)$ be the consumption of special insurance commodities. Among them, $E_{R}(t)$ is the consumption of insurance products entering life, and $E_{p}(t)$ is the consumption of insurance products entering production. Insurance investment cost is measured by consumption.

(4) Assuming that the production function $Y\left(K, L, E_{p}\right)$ is strictly concave, first-order homogeneous and second-order continuously differentiable. Since the population changes little in the short term, it can be assumed that the labor force $L$ is constant. Then, the production function should be a function of the physical capital $K$ and the insurance consumption $E_{p}(t)$ (calculated as a cost) into production, set to $Y\left(K, E_{p}\right)$. And there are:

$$
F\left(0, E_{P}\right)=F(K, 0)=0, F_{K E_{P}}=F_{E_{P} K}>0
$$

If consumption is divided into ordinary consumption and special consumption, it is assumed that special consumption is only insurance consumption. Then the total insurance consumption $\bar{E}$ composed of insurance entering production and consumption and insurance entering life consumption in a certain period, $\bar{E}$ remains unchanged. 
Generally speaking, insurance for production and consumption in poor areas is more than insurance for living consumption, developed regions have more insurance for production and consumption. Which is:

$$
E_{R}+E_{P}=\bar{E}
$$

Defining the consumption function $U\left(C, E_{R}\right): R_{+} \rightarrow R_{+}$is a nondecreasing function, and the consumption function is a secondorder continuous differentiable function with diminishing marginal utility. Let $\rho$ be the discount rate, then the utility function is

$$
\int_{0}^{\infty} U\left(C, E_{R}\right) e^{-\rho t} d t
$$

Then the above problem becomes to solve the following dynamic optimization problem:

$$
\left\{\begin{array}{l}
\max \int_{0}^{\infty} U\left(C, \bar{E}-E_{p}\right) e^{-\rho t} d t \\
\text { st. : } K=F\left(\dot{K}, E_{p}\right)-C-\delta K
\end{array}\right.
$$

Let $K(0)=K_{0}>0, C>0, E_{p} \geq 0, \lambda$ be the shadow price of capital, $\delta$ be the depreciation rate of physical assets, and the depreciation rate of monetary assets is 0 , then the Hamilton equation:

$$
H=U\left(C, \bar{E}-E_{P}\right)+\lambda\left[F\left(K, E_{P}\right)-C-\delta K\right]
$$

The necessary and sufficient conditions for the optimal path are:

$$
\left\{\begin{array}{c}
\lambda=U_{C}\left(C, \bar{E}-E_{P}\right) \\
U_{E_{R}}\left(C, \bar{E}-E_{P}\right)=\lambda F_{E_{P}}\left(K, E_{P}\right) \\
\dot{\lambda}=\lambda\left[\rho+\delta-F_{K}\left(E, E_{P}\right)\right]
\end{array}\right.
$$

Then there is $U_{E_{R}}=U_{C} F_{E_{p}}$, indicating that the marginal utility value of insurance used for personal household consumption must be equal to the marginal utility of ordinary consumption multiplied by the value of the marginal product of insurance for production and consumption of the enterprise.

Let $\dot{K}=\dot{\lambda}=0,{ }^{*}$ a represents the special solution of the variable in the steady-state, and the results are as follows:

$$
\left\{\begin{array}{c}
K=0=F\left(F^{*}, E_{p}^{*}\right)-C^{*}-\delta K^{*} \\
\dot{\lambda}==0=\lambda^{*}\left[\rho+\delta-F_{K}\left(K^{*}, E_{p}^{*}\right)\right]
\end{array}\right.
$$

When $\lambda^{*}>0$ then $\rho+\delta=F_{K}\left(K^{*}, E_{P}^{*}\right), C=F\left[K\left(E_{P}^{*}\right), E_{P}^{*}\right]-\delta K\left(E_{P}^{*}\right)$, from (6a) and (6b) we can get:

$$
\begin{aligned}
& U_{C} F\left\{\left[K\left(E_{P}^{*}\right), E_{P}^{*}\right]-\delta K\left(E_{P}^{*}\right), \bar{E}-E_{P}^{*}\right\} F_{E_{P}}\left[K\left(E_{P}^{*}\right), E_{P}^{*}\right] \\
& =U_{E_{P}}\left\{F\left[K\left(E_{P}^{*}\right), E_{P}^{*}\right]-\delta K\left(E_{P}^{*}\right), \bar{E}-E_{P}^{*}\right\}
\end{aligned}
$$

From Equation (8), the left is the total marginal productivity of insurance consumption $\left(\mathrm{VMP}_{E_{\mathrm{p}}}\right)$, and the right is the marginal cost of insurance products for production and consumption $\left(\mathrm{MC}_{E_{P}}\right)$. Then:

$$
\left\{\begin{array}{c}
\frac{d \mathrm{MC}_{E_{P}}}{d E_{P}}=U_{E_{R}} C\left[\left(F_{K}-\delta\right)\left(\frac{d K}{d E_{P}}\right)+F_{E_{P}}\right]-U_{E_{R} E_{R}} \\
\frac{d \mathrm{VMP}_{E_{P}}}{d E_{P}}=U_{C C} F_{E_{P}}\left[\left(F_{K}-\delta\right)\left(\frac{d K}{d E_{P}}\right)+F_{E_{P}}\right] \\
-U_{C E_{R}} F_{E_{P}}+U_{C}\left[F_{E_{P} E_{P}}-\left(\frac{F_{K E_{P}}^{2}}{F_{K K}}\right)\right]<0
\end{array}\right.
$$

It means that the production function is strictly concave, so in the steady-state, there are (1) $F_{K}-\delta=\rho$ is a positive value and $U_{C E_{p}}>0$. (2) In the interval $[0, \bar{E}], \mathrm{MC}_{E_{\mathrm{p}}}$ is a monotonically increasing function, and $\mathrm{VMP}_{E_{P}}$ is a monotonically decreasing function. Then:

$$
\left\{\begin{array}{c}
\frac{\partial C}{\partial K}=\left(\frac{-\lambda}{\Delta}\right)\left(F_{E_{P} K} U_{C E_{P}}\right)<0 \\
\frac{\partial E_{P}}{\partial K}=\left(\frac{-\lambda}{\Delta}\right)\left(F_{E_{P} K} U_{C C}\right)<0 \\
\Delta=\lambda F_{E_{P} E_{P}} U_{C C}+U_{E_{P} E_{R}} U_{C C}-U_{C E_{R}}^{2}>0
\end{array}\right.
$$

Because Equation (7b) shows that $F_{K E_{p}}>0$, the insurance of production and consumption is increasing. Therefore, Equations (10a) and (10c) show that when the stock of wealth capital increases, the marginal productivity of wealth capital decreases, and the marginal productivity must be less than $\rho+\delta$.

Moreover, there is an alternative relationship between insurance for production consumption and insurance for life consumption, in other words, there is an alternative relationship between a corporate annuity and personal commercial LTCI.

Also, since $U^{\prime \prime}(\cdot)<0$, then when consumption decreases, $U_{C}$ must increase. The larger the investment in the early stage of the production function, the greater the welfare for the elderly in the later stage, so the introduction of LTCI is extremely necessary.

As one of the leading cities in the megalopolis, Shanghai has strong regional advantages and economic strength. Policy subsidies and the participation of individuals can increase the benefits for the elderly.

\subsection{Analysis and Prediction of the Shanghai Population-based on GM $(1,1)$ Model}

The source of the data in this article is the total population of Shanghai registered household registration and the number of elderly people above 60 years of age who are registered in the Shanghai Statistical Yearbook from 2004 to 2017. It can be seen from Figure 1 that the degree of aging in Shanghai has been increasing year-by-year. Especially in 2014, its aging growth rate reached $6.33 \%$. Shanghai has reached a state of deep aging in 2015. Among them, the proportion of the population above 60 years old is $30.21 \%$. According to the data in Figure 1, a corresponding population prediction model is established by the gray prediction analysis theory below.

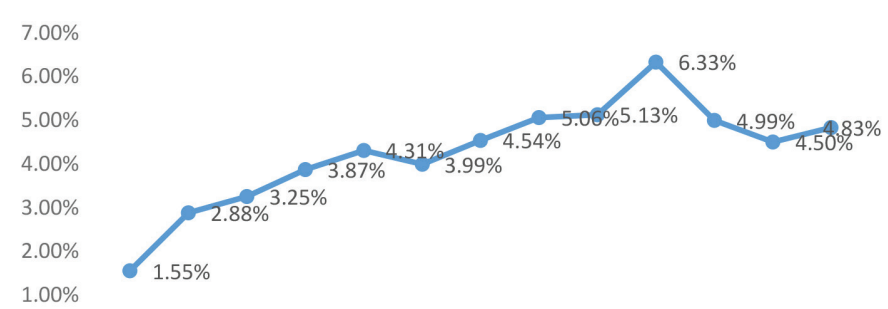

$0.00 \%$

2004200520062007200820092010201120122013201420152016

Figure 1 The growth rate of aging from 2004 to 2016. Data source: Shanghai Statistical Yearbook 2005-2017. 
First use the data of the elderly above 60 to form the original sequence:

$$
\begin{aligned}
& X^{(0)}(k)=\left[x^{(0)}(1), x^{(0)}(2), \ldots, x^{(0)}(14)\right] \\
& =\left[\begin{array}{l}
260.78,266.37,275.62,286.83,300.57,315.70,331.02, \\
347.76,367.32,387.62,413.98,435.95,457.80,481.61
\end{array}\right]
\end{aligned}
$$

Accumulate $x^{(0)}$ once and generate 1-AGO sequence:

$$
\mathrm{X}^{(1)}(k)=\left[x^{(1)}(1), x^{(1)}(2), \ldots, x^{(1)}(14)\right]
$$

where $x^{(1)}(k)=\sum_{i=1}^{k} x^{(0)}(i), k=1,2, \ldots, 14$

Let $Z^{(1)}=\left[Z^{(1)}(2), Z^{(1)}(3), \ldots, Z^{(1)}(14)\right]$ be the sequence generated by $X^{(1)}(k)$

where $z^{(1)}(k)=\frac{1}{2}\left[x^{(1)}(k)+x^{(1)}(k-1)\right], k=1,2, \ldots, 14$.

Construct two sets of matrices, respectively:

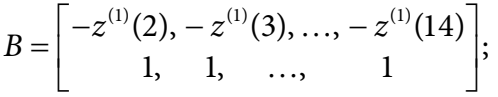

$$
\begin{aligned}
& Y_{n}=\left[x^{(0)}(2), x^{(0)}(3), \ldots, x^{(0)}(14)\right]
\end{aligned}
$$

The vector of coefficients to be estimated as $\hat{a}=\left(B^{T} B\right)^{-1} \cdot B^{T} \cdot Y_{n}$ Establish GM $(1,1)$ gray estimation model, its differential equation is:

$$
x^{(0)}(k)+a \times z^{(1)}(k)=b
$$

After generating the corresponding sequence of time, the corresponding variance is:

$$
\hat{x}^{(0)}(k+1)=\left[x^{(0)}(1)-\frac{b}{a}\right] \cdot e^{-a k}+\frac{b}{a}, k=1,2, \ldots, 13
$$

That is, the value of $\hat{a}=-0.00564432, \hat{b}=1354.727722$.

Then do cumulative subtraction reduction $\hat{x}^{(1)}(k+1)-\hat{x}^{(1)}(k)$ to calculate the corresponding value.

In the same way, for the estimation of Shanghai's registered population, let another original sequence:

$$
\begin{aligned}
& P^{(0)}(k)=\left[p^{(0)}(1), p^{(0)}(2), \ldots, p^{(0)}(14)\right] \\
& =\left[\begin{array}{l}
1352.39,1360.26,1368.08,1378.86,1391.04,1400.70,1412.32, \\
1419.36,1426.93,1432.34,1438.69,1442.97,1450.00,1455.13
\end{array}\right.
\end{aligned}
$$

Test the two levels:

$$
\begin{gathered}
\sigma(k)=\frac{x^{(0)}(k-1)}{x^{(0)}(k)}=\left[\begin{array}{l}
0.994214341,0.99428396,0.992181947, \\
0.991243961,0.993103448,0.991772403, \\
0.995040018,0.994694904,0.996222964, \\
0.995586263,0.997033895,0.995151724, \\
0.996474542
\end{array}\right] \\
\in\left(\frac{-2}{e^{n-1}}, \frac{2}{e^{n-1}}\right)=(0.875173319,1.142630812)
\end{gathered}
$$

Similarly, $\gamma(k)=\frac{p^{(0)}(k-1)}{p^{(0)}(k)} \in\left(\frac{-2}{e^{n-1}}, \frac{2}{e^{n-1}}\right)$. Then use $\hat{a}$ and $\sigma(k)$ to test the level ratio deviation value. The value is to meet higher requirements. Therefore, $X^{(0)}(k)$ and $P^{(0)}(k)$ can be used to construct a satisfactory gray prediction model.

Since only the data before 2018 is obtained, this article aims at the medium and long-term forecast, predicting the population distribution in the next 10 years (2017-2027) (Tables A1-A3). It can be seen that because this gray prediction model level ratio deviation value test has reached higher requirements, the population prediction is basically consistent with the original data, and the conclusion that the prediction data is credible can be drawn. The following analysis of the LTCI model is based on this data (Figure 2).

\subsection{Calculation of Nursing Needs}

\subsubsection{Calculation of disability of the elderly population}

Based on the above results of using the GM $(1,1)$ gray prediction model, this paper selects the sixth population census in Shanghai, and statistically collates the health and disability of the elderly population.

By calculating the corresponding distribution ratio, age is divided into three stages: $60-79$ years old and above 80 years old. Health status is measured by self-care ability, it is divided into the elderly who are not disabled, partially disabled and completely disabled and the latter two are the composition of the disability rate as shown in Table 2.

According to calculations, among the distribution of the elderly above 60 years old, $87.2711 \%$ are not disabled, $9.0208 \%$ are partially disabled; $3.7081 \%$ are completely disabled, and the disability rate is $12.289 \%$. The number of elderly disabled people and the number of people who need LTCI for the next 10 years from 2016 to 2027 are shown in Table 3.

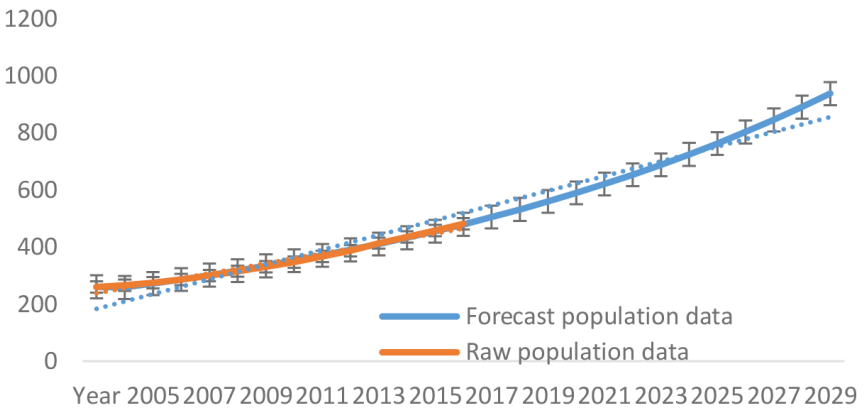

Figure 2 Simulation of the original population above 60 and the predicted population. Data source: Shanghai Statistical Yearbook 2005-2017.

Table 2 Distribution of disability among the elderly population

\begin{tabular}{lrrr}
\hline Age distribution & $\begin{array}{c}\text { 60-69 years } \\
\text { old (\%) }\end{array}$ & $\begin{array}{c}\text { 70-79 years } \\
\text { old (\%) }\end{array}$ & $\begin{array}{c}\text { Above 80 } \\
\text { years old (\%) }\end{array}$ \\
\hline Total & 100.0000 & 100.0000 & 100.0000 \\
Not disabled & 94.9725 & 85.1861 & 67.2086 \\
Partially disabled & 4.1806 & 11.3786 & 19.6793 \\
Completely disabled & 0.8469 & 3.4353 & 13.1121 \\
Disability rate & 5.0275 & 14.8139 & 32.7914 \\
\hline
\end{tabular}

Data source: The sixth population census in Shanghai. 
It can be seen from Figure 3 that both the completely disabled population and the partially disabled population are increasing. In particular, the partially disabled population has increased significantly, indicating that the number of people in need of moderate care in the future is relatively large. Under the rising trend of the elderly population in the future, it can be concluded that in the next 10 years, the number of LTCI needs will be about 60, accounting for $1 / 8$ of the elderly population.

\subsubsection{Elderly disabled population forecast for different care category}

The ratings of the disabled elderly in various regions of China are mainly assessed concerning the Barthel index, which is a commonly used internationally accepted Activities of Daily Living (ADLs). The treatment standards are mainly divided into three categories according to the degree of completely disability: (1) The first care category: the assessment level is two or three; (2) The second care category: the assessment level is four; (3) The third care category: the assessment level is five or six. With reference to the National Research on the Status of the Disabled Elderly in Urban and Rural Areas issued by the research group of the China Research Center

Table 3 2016-2027 Elderly disabled population and long-term care insurance (LTCI) demand forecast

\begin{tabular}{|c|c|c|c|c|c|}
\hline Year & $\begin{array}{c}\text { Population } \\
\text { above } 60 \\
(10,000 \\
\text { people) }\end{array}$ & $\begin{array}{c}\text { Partially } \\
\text { disabled } \\
(10,000 \\
\text { people })\end{array}$ & $\begin{array}{c}\text { Completely } \\
\text { disabled } \\
(10,000 \\
\text { people })\end{array}$ & $\begin{array}{c}\text { LTCI } \\
\text { demand } \\
\text { forecast } \\
(10,000 \\
\text { people) }\end{array}$ & $\begin{array}{c}\text { The current } \\
\text { number of } \\
\text { participants } \\
\text { in LTCI } \\
(10,000 \\
\text { people })\end{array}$ \\
\hline 2016 & 457.8000 & 41.2970 & 16.9758 & 58.2728 & $*$ \\
\hline 2017 & 481.6100 & 43.4448 & 17.8587 & 61.3036 & $*$ \\
\hline 2018 & 505.2430 & 45.5767 & 18.7351 & 64.3118 & 23.4 \\
\hline 2019 & 531.9568 & 47.9865 & 19.7256 & 67.7122 & 49.3 \\
\hline 2020 & 560.0831 & 50.5237 & 20.7686 & 71.2923 & $*$ \\
\hline 2021 & 589.6965 & 53.1951 & 21.8667 & 75.0618 & $*$ \\
\hline 2022 & 620.8757 & 56.0077 & 23.0229 & 79.0305 & $*$ \\
\hline 2023 & 653.7034 & 58.9690 & 24.2402 & 83.2091 & $*$ \\
\hline 2024 & 688.2668 & 62.0868 & 25.5218 & 87.6087 & $*$ \\
\hline 2025 & 724.6577 & 65.3696 & 26.8712 & 92.2408 & $*$ \\
\hline 2026 & 762.9727 & 68.8259 & 28.2920 & 97.1179 & $*$ \\
\hline 2027 & 803.3136 & 72.4649 & 29.7879 & 102.2528 & $*$ \\
\hline
\end{tabular}

Note: Forecast data after 2017. "represents data not yet available.

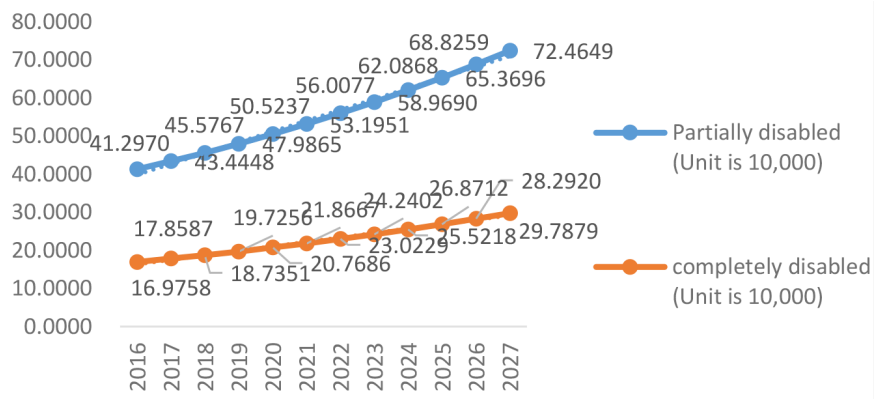

Figure 3 The evolution of the disabled elderly population forecast in Shanghai from 2016 to 2027. on Aging in 2011, it is pointed out that in 2010, the proportions of mild, moderate and severe disability of the completely elderly who in China were $84.3 \%, 5.1 \%$ and $10.6 \%$, respectively. Combining the nursing treatment standards in Shanghai, and based on the values in Table 3, we can get the predicted number of total disabled elderly care grade distribution in Shanghai from 2017 to 2027. It should be noted that since it is difficult to divide the standard of the number of partially disabled people, the number of partially disabled people is listed separately here, as shown in Table 4.

\subsubsection{Calculation of the number of home care workers required}

According to the payment policy of the Shanghai LTCI Fund, the payment levels for community care at home and elderly care institutions are $90 \%$ and $85 \%$ respectively. Inpatient medical care is mainly determined by actual conditions since the latter two contents vary greatly with actual conditions, this article selects the home care to estimate the nursing staff. The first care category, the second care category, and the third care category of nursing standards are mainly performed in the form of door-to-door services. The standards are three times a week, five times a week, and seven times a week and each service last $1 \mathrm{~h}$. If part of the disabled population is considered in the first type of care standard, based on the $40 \mathrm{~h}$ /week working hours per person, the number of nursing staff who need home care can be roughly estimated, as shown in Table 5.

\section{THE DILEMMA OF LONG-TERM CARE INSURANCE IN SHANGHAI}

\subsection{The Population Who Has Received Reimbursement from Long-term Care Insurance is Inadequate}

According to the data published in the "Shanghai Elderly Population and Elderly Career Monitoring Statistics Information" in 2018-2019,

Table 4 2016-2027 Elderly disabled population forecast for different care category

\begin{tabular}{lcccc}
\hline & & \multicolumn{3}{c}{ Completely disability $(\mathbf{1 0 , 0 0 0}$ people $)$} \\
\cline { 3 - 5 } Year & $\begin{array}{c}\text { Partially disabled } \\
(\mathbf{1 0 , 0 0 0} \text { people })\end{array}$ & $\begin{array}{c}\text { The first } \\
\text { care } \\
\text { category }\end{array}$ & $\begin{array}{c}\text { The second } \\
\text { care } \\
\text { category }\end{array}$ & $\begin{array}{c}\text { The third } \\
\text { care } \\
\text { category }\end{array}$ \\
\hline 2016 & 41.297 & 14.3106 & 0.865766 & 1.799435 \\
2017 & 43.4448 & 15.05488 & 0.910794 & 1.893022 \\
2018 & 45.5767 & 15.79369 & 0.95549 & 1.985921 \\
2019 & 47.9865 & 16.62868 & 1.006006 & 2.090914 \\
2020 & 50.5237 & 17.50793 & 1.059199 & 2.201472 \\
2021 & 53.1951 & 18.43363 & 1.115202 & 2.31787 \\
2022 & 56.0077 & 19.4083 & 1.174168 & 2.440427 \\
2023 & 58.969 & 20.43449 & 1.23625 & 2.569461 \\
2024 & 62.0868 & 21.51488 & 1.301612 & 2.705311 \\
2025 & 65.3696 & 22.65242 & 1.370431 & 2.848347 \\
2026 & 68.8259 & 23.85016 & 1.442892 & 2.998952 \\
2027 & 72.4649 & 25.1112 & 1.519183 & 3.157517 \\
\hline
\end{tabular}

Note: Forecast data after 2017 
Table 5 2016-2027 Calculation of the number of home care workers required

\begin{tabular}{llccl}
\hline Year & $\begin{array}{c}\text { The first } \\
\text { care category } \\
(\mathbf{1 0 , 0 0 0} \\
\text { people) }\end{array}$ & $\begin{array}{c}\text { The second } \\
\text { care category } \\
(\mathbf{1 0 , 0 0 0} \\
\text { people })\end{array}$ & $\begin{array}{c}\text { The third } \\
\text { care category } \\
(\mathbf{1 0 , 0 0 0} \\
\text { people) }\end{array}$ & $\begin{array}{c}\text { Total }(\mathbf{1 0 , 0 0 0} \\
\text { people) }\end{array}$ \\
\hline 2016 & 4.17057 & 0.108221 & 0.314901 & 4.59369188 \\
2017 & 4.387476 & 0.113849 & 0.331279 & 4.8326041 \\
2018 & 4.602779 & 0.119436 & 0.347536 & 5.06975168 \\
2019 & 4.846139 & 0.125751 & 0.36591 & 5.3377992 \\
2020 & 5.102372 & 0.1324 & 0.385258 & 5.62002973 \\
2021 & 5.372155 & 0.1394 & 0.405627 & 5.91718225 \\
2022 & 5.6562 & 0.146771 & 0.427075 & 6.23004573 \\
2023 & 5.955262 & 0.154531 & 0.449656 & 6.55944868 \\
2024 & 6.270126 & 0.162702 & 0.473429 & 6.90625693 \\
2025 & 6.601652 & 0.171304 & 0.498461 & 7.2714161 \\
2026 & 6.950705 & 0.180362 & 0.524817 & 7.6558826 \\
2027 & 7.318208 & 0.189898 & 0.552565 & 8.06067085 \\
\hline
\end{tabular}

Note: Forecast data after 2017

the number of people above 60 years old in Shanghai receiving nursing services in 2018 totaled 234,000 , accounting for $4.6 \%$ of the elderly population, the scope of the pilot program has been greatly expanded in 2019, and the number of elderly people above 60 years old in the city receiving nursing services totaled 493,000, accounting for $9.5 \%$ of the elderly population. From the results in Table 3, it can be concluded that the number of people in need of LTCI in 2018-2019 is much greater than the number of people in the pilot, the demand potential of LTCI is huge.

\subsection{Supporting Facilities for LTCI are Relatively Absent}

It can be seen from the above-predicted value that the difficulty of follow-up by nursing staff and nursing institutions is an important reason for the relatively lagging development of LTCI in China. Firstly, there is a large shortage of nursing staff in LTCI. Combined with the data from the Shanghai Statistical Yearbook and Table 5, the predicted number of nursing home care in 2018 alone will require more than 50,000 people, while the total number of health technicians in 2018 was only 206,500. If we add institutional care and inpatient medical care, it is unrealistic to rely solely on the current 206,500 people. Therefore, it can be judged that there is a huge shortage of nursing staff for LTCI. In terms of salaries, the 20152017 salaries of Shanghai residents' service, repair and other service industries were $33,720,37,292$, and 40,478 RMB per year respectively, which were lower than other industries such as agriculture, forestry, and animal husbandry. Currently, there are relatively few people working in health and social work, and people are more inclined to move to tertiary industries with higher salaries such as wholesale and retail, it can be seen that the promotion of LTCI still needs to be achieved by attracting salary. At the same time, if the government intends to train professional nursing talents, it needs to invest a lot of money. Secondly, the number of nursing institutions is still in a small share. In 2018, the number of elderly nursing homes and hospitals in Shanghai was only 38 and two, and the number of inpatients was 26,001 and 1863. Currently, the people who can participate in institutional care are elderly people

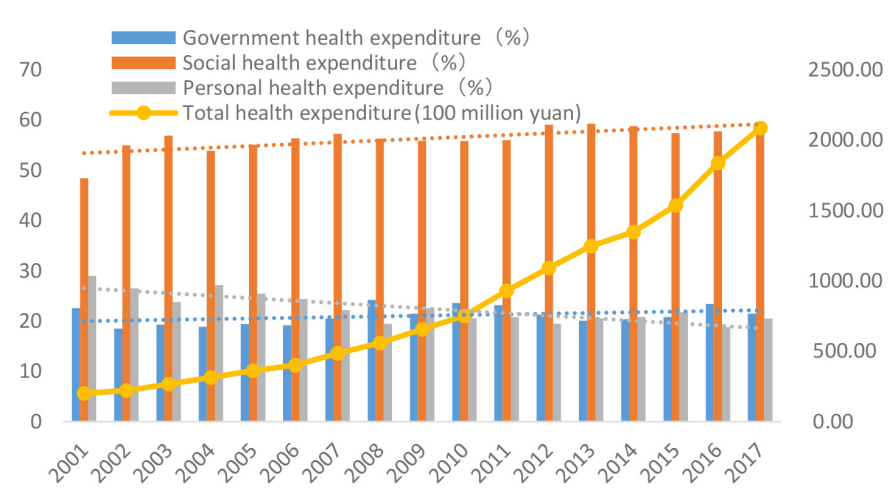

Figure 4 2004-2015 Shanghai health expenditure structure. Data source: Shanghai Statistical Yearbook 2005-2017.

with the third type of nursing standard. According to Table 4, the predicted number of people with the third care category in 2018 is close to 20,000, which is equivalent to the overall value of the current elderly care institution. The number is not enough to support the occupancy needs of the elderly with full weight disability, and the elderly with a severe disability still largely rely on home care.

\subsection{The Burden Structure of Health Expenses is Under Certain Pressure}

Since the implementation of the LTCI pilot program is closely related to medical resources, public health expenditures can be used as a reference standard. As shown in Figure 4, Shanghai's public health expenditures have been on the rise, and the trend is that the proportion of personal health expenditures has fallen, staying at about $20 \%$, while the proportions of government health expenditures and social health expenditures have been increasing. The health expenses of Shanghai LTCI are mainly paid by the special LTCI Fund, which is a new fiscal expenditure item. The long-term care policy based on aging will have a certain impact on Shanghai's fiscal expenditure. Correspondingly, due to the impact of the COVID-19 in China in 2020, the national medical resources may further participate in the fight against the epidemic, which will greatly increase the corresponding health expenses. Therefore, the expenditure on health expenditure is uncertain. Despite this, we can still analyze the severity of the elderly population, and more public expenditure on health can be foreseen in the next 10 years (Table A4).

In summary, LTCI needs corresponding aging care needs to exist objectively, meanwhile, the implementation of the policy is under great pressure: the shortage of nursing staff and the low salary, the impact of the special fund for LTCI on fiscal expenditures, and the collateral effect of COVID-19 have increased the uncertainty of public health expenditure.

\section{CONCLUSION AND PROSPECT}

This paper uses the GM $(1,1)$ model to predict and analyze the total registered population and the number of elderly people aged 60 years and above in Shanghai in the next 10 years, combined with the health of the elderly population above 60 years old in the sixth 
census of Shanghai in 2010. Based on the census data, this article mainly draws the following conclusions:

Theoretical derivation shows that LTCI is affected by regional economic and socio-economic conditions in megacities. The micropath and difference between LTCI products entering the enterprise production field and the household consumption field, among them, production insurance consumption depends on changes in wealth and capital stock. The larger the capital stock, the more production insurance consumption.

Empirical research shows that, first of all, the predicted population of long-term care needs in Shanghai can be obtained by calculation, which is much higher than the actual participating population in 2018 and 2019. The current gap in LTCI is large, especially for some disabled population. The largest increase indicates that the number of people in need of moderate care in the future is large, and the supply of mid-term care should be considered. Secondly, through the calculation of the expected number of people with disabilities in the nursing level and the corresponding number of people in Shanghai, combined with the current service industry salary, it is found that the nursing staff of LTCI has a large gap and low salary. Moreover, the number of corresponding nursing institutions is extremely small, and the degree of institutional care is low, which is not enough to support the current occupancy needs of disabled people for institutional care. Third, there is a certain pressure on the burden structure of Shanghai's health expenses. Lastly, there is a certain pressure on the burden structure of Shanghai's health expenses. The special fund expenditure for LTCI and the effect of COVID-19 have increased the uncertainty of public health expenditures. If the government increases the implementation of LTCI, it will inevitably increase the corresponding public resource expenditures. Several factors may exert a certain pressure on the development of long-term protection insurance.

Based on the above conclusions, this article gives the following suggestions:

To begin with, based on the results of theoretical derivation, the promotion of long-term protection insurance should be carried out with the idea of "large-medium-small" urban agglomerations. Good regional economy and material conditions are conducive to the consumption of LTCI. The first promotion of LTCI in big cities is to lay the foundation and to explore suitable development experience and consumption stock, which may be more beneficial to small and medium-sized cities.

Secondly, is to build a medical security system for LTCI for the elderly and improve supporting facilities. The increase in the degree of aging will promote health expenditures, especially after the outbreak of the new crown epidemic, the larger increase in health expenditures is foreseeable. In terms of public resources, China's future trend is to further reduce personal health expenditures, the government should fully consider the proportion of personal contributions and medical pooling funds, and plan the corresponding resource allocation. In terms of the supply of supporting facilities, the salary of nursing staff should be appropriately increased based on the investment in pension welfare institutions and medical institutions.

Last but not least, it is to encourage corresponding commercial insurance policies to complement. On the one hand, from the above data, it can be seen that the government is facing greater pressure to build a comprehensive LTCI social security system, thus, we suggest to cooperate with commercial insurance companies to fully mobilize resources for LTCI exploration and play a complementary role in social security. On the other hand, is to actively try to combine with the corresponding pilot system, such as the possibility of combining with the housing pension system: Is it possible for the elderly to reverse mortgage the property and move into the designated institution of LTCI?

In summary, whether it is the form of universal social insurance in Japan or the mode of political and commercial cooperation in the United States, its core cannot be separated from the needs of people with LTCI. China's current LTCI policy, in essence, is to draw lessons from the foreign pension system, the mode and development process of the implementation of foreign countries, are worth learning experience, especially on the elderly insurance group needs and the potential number of insurance. In the exploration of LTCI, for the insured, the degree of policy awareness is one aspect, and the definition of the insured population is another aspect. On the national side, the needs for the construction of pilot nursing service manpower, material resources, and the elderly care environment are worthy of in-depth exploration. Starting from the perspective of participants, it is extremely necessary to build a system that covers their health awareness, economic awareness, and policy awareness.

\section{CONFLICTS OF INTEREST}

The authors declare they have no conflicts of interest.

\section{REFERENCES}

[1] Tamiya N, Noguchi H, Nishi A, Reich MR, Ikegami N, Hashimoto $\mathrm{H}$, et al. Population aging and wellbeing: lessons from Japan's long-term care insurance policy. Lancet 2011;378:1183-92.

[2] Wasem J. A study on decentralizing from acute care to home care settings in Germany. Health Policy 1997;41:S109-S29.

[3] Rhee JC, Done N, Anderson GF. Considering long-term care insurance for middle-income countries: comparing South Korea with Japan and Germany. Health Policy 2015;119:1319-29.

[4] Launois R. Pooling public and private funds in the patient's interest: the case for long-term care insurance. Soc Sci Med 1996;43:739-44.

[5] German Insurance Association. Statistical Yearbook of German Insurance 2016. 2016. Available from: https://www.nextdeal.gr/ PDFS/ereunes/Stat_Yearbook_2016.pdf.

[6] Umegaki H, Yanagawa M, Nonogaki Z, Nakashima H, Kuzuya M, Endo H. Burden reduction of caregivers for users of care services provided by the public long-term care insurance system in Japan. Arch Gerontol Geriatr 2014;58:130-3.

[7] LIMRA, U.S. Group Long-Term Care Insurance Executive Summary. Annual 2005. 2005. Available from: https://www. limra.com/en/research/research-abstracts/Classics/2006/u.s.group-long-term-care-insurance-2005-annual/.

[8] Ministry of Health, Labor and Welfare. Long-Term Care Insurance System of Japan, Health and Welfare Bureau for the Elderly Ministry of Health, Labor and Welfare. 2016. Available from: https://www.mhlw.go.jp/english/policy/care-welfare/care-welfareelderly/index.html.

[9] Gupta A, Li L. A modeling framework for optimal long-term care insurance purchase decisions in retirement planning. Health Care Manag Sci 2004;7:105-17. 
[10] Pauly MV. The rational nonpurchase of long-term-care insurance. J Polit Econ 1990;98:153-68. Available from: https://www. jstor.org/stable/2937646.

[11] Zweifel P, Strüwe W. Long-term care insurance and bequests as instruments for shaping intergenerational relationships. J Risk Uncertain 1996;12:65-76.

[12] Zissimopoulos J. Resource transfers to the elderly: do adult children substitute financial transfers for time transfers?. Santa Monica, CA: RAND Corporation; 2001. Available from: https:// www.rand.org/pubs/drafts/DRU2542.html.

[13] Sloan FA, Zhang HH, Wang J. Upstream intergenerational transfers. South Econ J 2002;69:363-80.

[14] Pestieau P, Sato M, 主光 佐藤. Long-term care: the state, the market and the family. SSRN Electronic J 2004.

[15] Barnett AE, Stum MS. Spousal decision making and long-term care insurance. J Financial Couns Plan 2013;24:5-19.

[16] Coe NB, Skira MM, Van Houtven CH. Long-term care insurance: does experience matter? J Health Econ 2015;40:122-31.

[17] Guangzong M, Tuan Z. The development trend of my country's population aging and its strategic response. J Central China Norm Univ (Human Soc Sci Ed) 2011;50:29-36.

[18] Jie C. Nursing insurance in Japan and its enlightenment. Market Demogr Anal 2002;2:69-73.

[19] Tao J. Long-term care insurance research. Beijing, China: University of International Business and Economics; 2005.

[20] Weidong D. The theory and model of long-term care insurance system. People's Forum 2011;29:31-4.

[21] Man Z, Li H. The choice of long-term care insurance system: a research review. China Popul Sci 2015;1:97-105+128.

\section{APPENDIX}

Table A1 Shanghai's total registered population and aging growth rate

\begin{tabular}{lcccc}
\hline Year & $\begin{array}{c}\text { Total } \\
\text { population } \\
(\mathbf{1 0 , 0 0 0} \text { people) }\end{array}$ & $\begin{array}{c}\text { Population } \\
\text { above 60 } \\
(\mathbf{1 0 , 0 0 0} \text { people) }\end{array}$ & $\begin{array}{c}\text { Proportion } \\
\text { above 60 (\%) }\end{array}$ & $\begin{array}{c}\text { Aging growth } \\
\text { rate (\%) }\end{array}$ \\
\hline 2004 & 1352.39 & 260.78 & 19.28 & - \\
2005 & 1360.26 & 266.37 & 19.58 & 1.55 \\
2006 & 1368.08 & 275.62 & 20.15 & 2.88 \\
2007 & 1378.86 & 286.83 & 20.80 & 3.25 \\
2008 & 1391.04 & 300.57 & 21.61 & 3.87 \\
2009 & 1400.70 & 315.70 & 22.54 & 4.3 \\
2010 & 1412.32 & 331.02 & 23.44 & 3.99 \\
2011 & 1419.36 & 347.76 & 24.50 & 4.54 \\
2012 & 1426.93 & 367.32 & 25.74 & 5.06 \\
2013 & 1432.34 & 387.62 & 27.06 & 5.13 \\
2014 & 1438.69 & 413.98 & 28.77 & 6.33 \\
2015 & 1442.97 & 435.95 & 30.21 & 4.99 \\
2016 & 1450.00 & 457.80 & 31.57 & 4.50 \\
2017 & 1455.13 & 481.61 & 33.10 & 4.83 \\
\hline
\end{tabular}

Data source: "Shanghai Statistical Yearbook 2004-2018" obtained after calculation, corresponding to Figure 1 in the article.
[22] Minglai Z, Xinping L. The exploration of nursing insurance in China. Beijing: China Financial and Economic Publishing House; 2017, pp. 108-22.

[23] Amilon A, Ladenburg J, Siren A, Østergaard SV. Willingness to pay for long-term home care services: evidence from a stated preferences analysis. J Econ Ageing 2020;17;100238.

[24] He AJ, Chou KL. What affects the demand for long-term care insurance? A study of middle-aged and older adults in Hong Kong. J Appl Gerontol 2020;39:413-22.

[25] Courbage C, Roudaut N. Empirical evidence on long-term care insurance purchase in France. Geneva Pap Risk Insur Issues Pract 2008;33:645-58.

[26] Brown JR, Finkelstein A. The private market for long-term care insurance in the United States: a review of the evidence. J Risk Insur 2009;76:5-29.

[27] Youlu X. Analysis of factors affecting the demand of long-term nursing insurance in China. Finance Econ 2012;11:75-8.

[28] Xinbang C, Qiang C. Analysis of the factors affecting the demand for long-term care insurance in China. China Popul Sci 2014;4: $102-109+128$.

[29] Zhihong D, Haiwei W. The willingness of Chinese urban elderly to purchase long-term care insurance and its influencing factors. Popul Res 2016;40:76-86.

[30] $\mathrm{Pu}$ C. China's insurance industry optimal growth research. Beijing: China Finance and Economics Publishing House; 2008, pp. 116-19.

[31] Hongye G. Western Economics (Science Micro Part). 5th ed. Beijing: Renmin University of China Press; 2000, pp. 103-4.

[32] Nicholson W, Snyder C. Microeconomic theory: basic principles and extensions. Beijing: Peking University Press; 2008, pp. 91-113.

Table A2 Population forecast

\begin{tabular}{lcc}
\hline Year & $\begin{array}{c}\text { Original population } \\
(\mathbf{1 0 , 0 0 0} \text { people })\end{array}$ & $\begin{array}{c}\text { Predicted population } \\
(\mathbf{1 0 , 0 0 0} \text { people })\end{array}$ \\
\hline 2004 & 1352.39 & 1352.39 \\
2005 & 1360.26 & 1373.946237 \\
2006 & 1368.08 & 1381.723156 \\
2007 & 1378.86 & 1389.544095 \\
2008 & 1391.04 & 1397.409303 \\
2009 & 1400.70 & 1405.31903 \\
2010 & 1412.32 & 1413.273528 \\
2011 & 1419.36 & 1421.273051 \\
2012 & 1426.93 & 1429.317853 \\
2013 & 1432.34 & 1437.408192 \\
2014 & 1438.69 & 1445.544324 \\
2015 & 1442.97 & 1453.726508 \\
2016 & 1450.00 & 1461.955006 \\
2017 & 1455.13 & 1470.23008 \\
2018 & $*$ & 1478.551993 \\
2019 & $*$ & 1486.92101 \\
2020 & $*$ & 1495.337398 \\
2021 & $*$ & 1503.801426 \\
2022 & $*$ & 1512.313362 \\
\hline
\end{tabular}


Table A2 Population forecast-Continued

\begin{tabular}{ccc}
\hline Year & $\begin{array}{c}\text { Original population } \\
(\mathbf{1 0 , 0 0 0} \text { people })\end{array}$ & $\begin{array}{c}\text { Predicted population } \\
(\mathbf{1 0 , 0 0 0} \text { people })\end{array}$ \\
\hline 2023 & $*$ & 1520.873478 \\
2024 & $*$ & 1529.482046 \\
2025 & $*$ & 1538.139342 \\
2026 & $*$ & 1546.84564 \\
2027 & $*$ & 1555.601219 \\
\hline
\end{tabular}

\begin{tabular}{lcl}
\hline Year & $\begin{array}{c}\text { Original population } \\
\text { above } \mathbf{6 0}(\mathbf{1 0 , 0 0 0} \\
\text { people) }\end{array}$ & $\begin{array}{c}\text { Predicted population } \\
\text { above } \mathbf{6 0}(\mathbf{1 0 , 0 0 0} \text { people) }\end{array}$ \\
\hline 2004 & 260.78 & 260.78 \\
2005 & 266.37 & 258.5896295 \\
2006 & 275.62 & 272.2621027 \\
2007 & 286.83 & 286.657484 \\
2008 & 300.57 & 301.8139958 \\
2009 & 315.7 & 317.7718816 \\
2010 & 331.02 & 334.5735126 \\
2011 & 347.76 & 352.2635005 \\
2012 & 367.32 & 370.8888154 \\
2013 & 387.62 & 390.4989111 \\
2014 & 413.98 & 411.1458563 \\
2015 & 435.95 & 432.8844725 \\
2016 & 457.8 & 455.77248 \\
2017 & 481.61 & 479.8706506 \\
2018 & $*$ & 505.2429698 \\
2019 & $*$ & 531.9568059 \\
2020 & $*$ & 560.0830893 \\
2021 & $*$ & 589.6965005 \\
2022 & $*$ & 620.875669 \\
2023 & $*$ & 653.7033813 \\
2024 & $*$ & 688.2668013 \\
2025 & $*$ & 724.6577016 \\
2026 & $*$ & 762.9727068 \\
2027 & $*$ & 803.3135509 \\
\hline
\end{tabular}

\begin{tabular}{ccc}
\hline Year & $\begin{array}{c}\text { Original proportion } \\
\text { above } \mathbf{6 0}(\mathbf{\%})\end{array}$ & $\begin{array}{c}\text { Predicted proportion } \\
\text { above } \mathbf{6 0}(\mathbf{\%})\end{array}$ \\
\hline 2004 & 19.28 & 19.28 \\
2005 & 19.58 & 18.82 \\
2006 & 20.15 & 19.70 \\
2007 & 20.80 & 20.63 \\
2008 & 21.61 & 21.60 \\
2009 & 22.54 & 22.61 \\
2010 & 23.44 & 23.67 \\
2011 & 24.50 & 24.79 \\
2012 & 25.74 & 25.95 \\
2013 & 27.06 & 27.17 \\
2014 & 28.77 & 28.44 \\
2015 & 30.21 & 29.78 \\
2016 & 31.57 & 31.18 \\
2017 & 33.10 & 32.64 \\
2018 & $*$ & 34.17 \\
2019 & $*$ & 35.78 \\
2020 & $*$ & 37.46 \\
2021 & $*$ & 39.21 \\
2022 & $*$ & 41.05 \\
2023 & $*$ & 42.98 \\
2024 & $*$ & 45.00 \\
2025 & $*$ & 47.11 \\
2026 & $*$ & 49.32 \\
2027 & $*$ & 51.64 \\
\hline
\end{tabular}

Note: Forecast data after 2017, corresponding to Figure 2 in the article. *represents data not yet available.
Table A3 Distribution of disability among the elderly population

\begin{tabular}{|c|c|c|c|c|c|}
\hline $\begin{array}{l}\text { Age } \\
\text { distribution }\end{array}$ & $\begin{array}{c}\text { Total } \\
(10,000 \\
\text { people })\end{array}$ & $\begin{array}{c}\text { Health } \\
(10,000 \\
\text { people })\end{array}$ & $\begin{array}{c}\text { Not } \\
\text { disabled } \\
(10,000 \\
\text { people })\end{array}$ & $\begin{array}{c}\text { Partially } \\
\text { disabled } \\
(10,000 \\
\text { people })\end{array}$ & $\begin{array}{c}\text { Completely } \\
\text { disabled } \\
(10,000 \\
\text { people })\end{array}$ \\
\hline Total & 345592 & 150971 & 150631 & 31175 & 12815 \\
\hline $\begin{array}{l}\text { 60-64 years } \\
\text { old }\end{array}$ & 113829 & 71877 & 37371 & 3842 & 739 \\
\hline $\begin{array}{l}65-69 \text { years } \\
\text { old }\end{array}$ & 66121 & 34007 & 27648 & 3681 & 785 \\
\hline $\begin{array}{l}\text { 70-74 years } \\
\text { old }\end{array}$ & 52401 & 19720 & 26785 & 4679 & 1217 \\
\hline $\begin{array}{l}\text { 75-79 years } \\
\text { old }\end{array}$ & 55363 & 15428 & 29867 & 7583 & 2485 \\
\hline $\begin{array}{l}\text { 80-84 years } \\
\text { old }\end{array}$ & 34796 & 6714 & 18462 & 6468 & 3152 \\
\hline $\begin{array}{l}\text { 85-89 years } \\
\text { old }\end{array}$ & 16979 & 2606 & 8119 & 3607 & 2647 \\
\hline $\begin{array}{l}\text { 90-94 years } \\
\text { old }\end{array}$ & 5071 & 538 & 2050 & 1105 & 1378 \\
\hline $\begin{array}{l}\text { 95-99 years } \\
\text { old }\end{array}$ & 958 & 76 & 301 & 201 & 380 \\
\hline $\begin{array}{l}\text { Above } 100 \\
\text { years old }\end{array}$ & 74 & 5 & 28 & 9 & 32 \\
\hline
\end{tabular}

Table A4 Health expenditure in Shanghai

\begin{tabular}{ccc}
\hline Year & $\begin{array}{c}\text { Total health } \\
\text { expenditure } \\
\text { (billion yuan) }\end{array}$ & $\begin{array}{c}\text { Health expenditure } \\
\text { increase in volume } \\
\text { (billion yuan) }\end{array}$ \\
\hline 2004 & 315.48 & - \\
2005 & 362.13 & 46.65 \\
2006 & 401.46 & 39.33 \\
2007 & 485.67 & 84.21 \\
2008 & 559.83 & 74.16 \\
2009 & 656.66 & 96.83 \\
2010 & 751.99 & 95.33 \\
2011 & 931 & 179.01 \\
2012 & 1092.35 & 161.35 \\
2013 & 1248.68 & 156.33 \\
2014 & 1347.79 & 99.11 \\
2015 & 1536.6 & 188.81 \\
2016 & 1838 & 301.4 \\
\hline
\end{tabular}

Data source: Shanghai Bureau of Statistics, corresponding to Figure 4 in the article. 